\title{
The thrombotic microangiopathies
}

\author{
Lawrence Copelovitch • Bernard S. Kaplan
}

Received: 18 May 2007 /Revised: 20 July 2007 / Accepted: 27 July 2007 /Published online: 30 September 2007

(C) IPNA 2007

\begin{abstract}
The term thrombotic microangiopathy (TMA) encompasses a group of conditions that are defined by, or result from, a similar histopathological lesion. Hemolytic uremic syndrome (HUS), thrombotic thrombocytopenic purpura (TTP), and several other conditions are associated with TMA. Distinguishing HUS from TTP is not always possible unless there are specific causes, such as Shiga toxin, Streptococcus pneumoniae, or a specific molecular defect such as factor $\mathrm{H}$ or ADAMTS13 deficiency. This review describes the forms of HUS/TTP that are not related to Shiga toxin, pneumococcal infection, genetic causes, or ADAMTS13 deficiency. Conditions include HUS/TTP associated with autoimmune disorders, human immunodeficiency virus (HIV) infection, transplantation, malignancy, and medications.
\end{abstract}

Keywords Thrombotic microangiopathy .

Hemolytic uremic syndrome .

Thrombotic thrombocytopenic purpura

\section{Introduction}

Hemolytic uremic syndrome (HUS) is defined as the triad of microangiopathic hemolytic anemia, thrombocytopenia, and acute renal injury. Thrombotic thrombocytopenic purpura (TTP) is characterized by the pentad of microangiopathic hemolytic anemia, thrombocytopenia, fever, acute renal injury, and neurological abnormalities. Generally,

L. Copelovitch $\cdot$ B. S. Kaplan $(\bowtie)$

Department of Pediatrics, Division of Nephrology,

The Children's Hospital of Philadelphia,

34th Street and Civic Center Boulevard,

Philadelphia, PA 19104, USA

e-mail: kaplanb@email.chop.edu renal manifestations predominate in HUS, and neurological features are important in TTP. It is also clear that there are many types of HUS and TTP that can now be defined not only by these classical criteria but, more precisely, by known etiological factors [1]. It is accepted that there are clinicopathological entities called Shiga toxin HUS, pneumococcal HUS (see the Teaching Article on this entity), and genetic (inherited, familial) HUS with deficiencies of factors H, I, B or membrane cofactor protein. There are also acquired and constitutive deficiencies in the activities of von Willebrand factor (vWF) cleaving protease (ADAMTS13) that result in TTP.

However, there are other syndromes that do not fall easily under the above rubrics. In 1952 Symmers introduced the all-encompassing term thrombotic microangiopathy (TMA). This term helps us to address some of the ambiguities that defy clinical classification [2]. TMA describes a pattern of arteriolar thrombi, with intimal swelling and fibrinoid necrosis of the vessel wall [3]. TMA in its broadest definition is the histopathological feature of HUS and TTP; however, the composition of the thrombi differs markedly between well-defined types of HUS and TTP. The thrombi in Shiga toxin HUS are rich in fibrin, whereas those in TTP are mainly composed of vWF and degranulated platelets [4]. TMA is also observed in several other conditions, including systemic lupus erythematosus (SLE), malignancy, disseminating intravascular coagulopathy (DIC), and pre-eclampsia (Fig. 1). TMA is a final pathological endpoint that results from a disruption of the normal platelet-endothelial interface [5]. This can occur either through direct vascular endothelial wall damage by Shiga toxin or Thomsen-Friedenreich antigen activation (pneumococcal HUS), or from a defect in normal plasma regulatory systems, such as factor $\mathrm{H}$ deficiency or ADAMTS13 deficiency. 


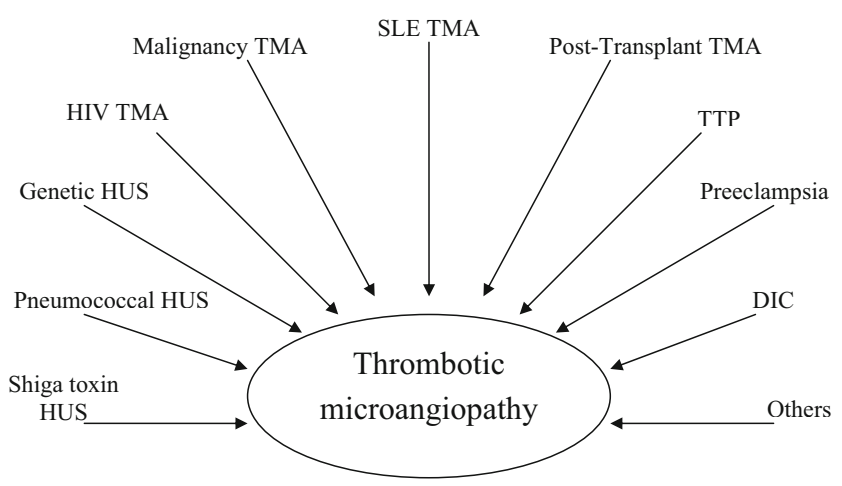

Fig. 1 Thrombotic microangiopathies

Our approach is to classify HUS as: 1. Shiga toxin HUS; 2. Pneumococcal HUS; 3. Genetic HUS; 4. HUS and/or TTPlike forms of TMA not associated with decreased levels of ADAMTS13. In this review we discuss the diverse group of conditions that we refer to as the non-Shiga toxin, nonpneumococcal, non-genetic, non-ADAMTS13-deficient forms of HUS or TTP. To get around this cumbersome designation, we will use the term HUS/TTP to encompass these cases that would be more accurately classified in the broader category of TMA. These rare conditions include HUS/TTP associated with autoimmune disorders, human immunodeficiency virus (HIV) infection, transplantation, malignancy, and medications.

Rigorous classification of TMA is important, because of the implications for treatment. Patients with genetic HUS that result from congenital deficiencies of complement pathway regulators, or congenital TTP that result from a congenital deficiency of ADAMTS13, may benefit from the replacement of these factors through plasma infusions. Patients with acquired TTP may benefit from plasma exchange by the removal of the vWF-cleaving protease inhibitors, thereby restoring ADAMTS13 levels. There is no proven benefit for plasma infusions or plasmapheresis in Shiga toxin HUS or pneumococcal HUS. Furthermore, there is no proven benefit for plasma infusions or plasmapheresis in HUS/TTP associated with autoimmune disorders, human immunodeficiency virus (HIV) infection, transplantation, malignancy, or medications.

\section{Autoimmune disorders}

TMA occasionally occurs in SLE [6-8] and antiphospholipid antibody syndrome (APLS) [9] and rarely in many autoimmune disorders (Table 1).

Clinical features and diagnosis

Approximately 60 cases of TMA associated with SLE are reported [6-8]. Mirroring the demography of SLE, the majority of the patients are female adolescents or young
Table 1 Autoimmune disorders associated with TMA

\begin{tabular}{ll}
\hline Systemic lupus erythematosus & $\begin{array}{l}\text { Antiphospholipid antibody } \\
\text { syndrome }\end{array}$ \\
\hline $\begin{array}{l}\text { Scleroderma } \\
\text { Mixed connective tissue } \\
\text { disease }\end{array}$ & $\begin{array}{l}\text { Sjögren syndrome } \\
\text { Dermatomyositis }\end{array}$ \\
$\begin{array}{l}\text { Rheumatoid arthritis } \\
\text { Behçet disease }\end{array}$ & Ankylosing spondylarthritis \\
Myasthenia gravis & $\begin{array}{l}\text { Polyarteritis nodosa } \\
\text { Ulcerative colitis }\end{array}$ \\
& $\begin{array}{l}\text { Adult Still's disease } \\
\text { Idiopathic thrombocytopenic } \\
\text { purpura }\end{array}$ \\
\end{tabular}

adults [6]. The onset of SLE often precedes HUS/TTP ( $>60 \%$ ); but HUS/TTP may occur simultaneously or precede SLE [6]. From $1-4 \%$ of patients with SLE have an episode of HUS/TTP during their illness [7, 10], but one autopsy study found a prevalence of $14 \%$, suggesting that the diagnosis of HUS/TTP may be overlooked [11]. This might occur because HUS/TTP and SLE have overlapping clinical features, including hemolytic anemia, thrombocytopenia, fever, neurological dysfunction, and renal impairment. However, SLE, per se, is not associated with a microangiopathic hemolytic anemia characterized by schistocytes. When hemolytic anemia and thrombocytopenia occur in SLE in the absence of schistocytes, they are usually accompanied by positive findings in a Coombs' test and by anti-platelet antibodies. A positive result for a Coombs' test does not exclude the diagnosis of HUS/TTP.

\section{Pathogenesis}

The exact pathogenesis of SLE associated TMA (SLETMA) remains unknown and may differ between patients. Zheng et al. [10] reported a severe deficiency of ADAMTS13 in $80 \%$ of patients with TTP and in none of those with autoimmune-, transplantation-, malignancy-, medication-, or pregnancy-associated (secondary forms) of TTP. However, only one of the patients with secondary TTP had SLE-TMA. In contrast, in a study of the ADAMTS13 levels of 15 patients with autoimmune disease-associated TMA (SLE, APLS, thyroiditis, psoriasis, Crohn disease), seven had undetectable ADAMTS13 levels, five had normal levels, and three had intermediate levels [12]. Furthermore, seven had inhibitors of the vWFcleaving protease. In addition, the development of SLETMA may be the result of a more generalized autoimmune process that results in direct endothelial injury, with antiendothelial antibodies [12]. The direct endothelial damage might lead to reduced prostacyclin synthesis, platelet activation and $\mathrm{vWF}$ abnormalities, resulting in TMA [8].

APLS autoantibodies are also implicated in the development of SLE-TMA. Although some patients with SLETMA have a positive antiphospholipid antibody panel, 
these antibodies may be found in up to $50 \%$ of all patients with SLE [13]. Whether APLS contributes to disease development in some SLE-TMA patients is unclear. Further complicating matters, two patients with primary APLS (without SLE) developed HUS/TTP in association with a severe deficiency of ADAMTS13 and the presence of a vWF-cleaving protease inhibitor [9]. The great difficulty in unraveling the pathogenesis of these conditions is the result of clinically overlapping picture of HUS/TTP, SLE, and APLS, the possibility that these conditions might coexist, and the possibility that ADAMTS13 levels might be depressed in many conditions.

\section{Treatment}

There is no established guideline for the treatment of SLETMA. Plasma exchanges, prednisone, and cyclophosphamide are the most frequent choices of therapy [7]. The overall mortality rate among 56 patients with SLE-TMA was 33.9\% [6]. In this review the mortality rate of the subset of patients treated with plasmapheresis or plasma exchange was $31.9 \%$, compared with $44.4 \%$ in a group not treated with plasmapheresis or plasma exchange. While plasmapheresis may reduce the mortality rate in SLE-TMA, it is not as effective as in TTP, where the mortality rate in treated patients is $<10 \%$. Because of the limited number of reported cases of APLS-TMA there is no standard of care [14].

\section{Human immunodeficiency virus}

\section{Clinical features and diagnosis}

HUS/TTP has been reported in several hundred HIV-infected adults [15]. The confounding clinical spectrum of acquired immunodeficiency syndrome (AIDS) with autoimmune thrombocytopenia, myelodysplasia, central nervous system dysfunction, HIV nephropathy, medication exposure, opportunistic infections, and secondary malignancies often makes the diagnosis of HIV-associated TMA (HIV-TMA) confusing [16]. The prevalence of TMA in adult HIV patients is $7 \%$ to $35 \%[17,18]$, but it is rare in childhood [19].

\section{Pathogenesis}

There are reports of HIV-TMA with ADAMTS13 deficiency and inhibitors of the vWF-cleaving protease [16], but the ADAMTS13 levels were not measured in most cases. The best evidence for the importance of ADAMTS13 deficiency in HIV-TMA is in the possible response to plasma infusion therapy [20]. Alternatively, the pathogenesis of HIV-TMA may be the result of a primary endothelial injury. Whether the endothelial damage is directly related to viral infection of the microvasculature and renal cells or is indirectly related to altered vasoactive factors, local coagulation defects, inflammatory injury, or direct damage from HIV subunit peptides (Tat, gp120), is unclear [15].

Treatment

There is no consensus on the optimal treatment of HIVTMA. Plasmapheresis/plasma exchange is the most widely employed therapy, but the results are mixed $[15,20]$. Some clinicians feel that there is no compelling case for any therapy above and beyond routine HIV treatment and supportive care [15].

\section{Transplantation}

Clinical features and diagnosis

Post-transplantation TMA may be the result of recurrent disease or a de novo event. Recurrent TMA is usually associated with genetic forms of HUS. De novo TMA can occur after hematopoietic stem cell transplantation (HSCT) or solid organ transplantation. The incidence of TMA after allogenic HSCT (HSCT-TMA) is $0.5 \%$ to $76 \%$ [21]. The estimated prevalence is $8.2 \%$, with a median mortality of $75 \%$ [22]. The median onset is 44 days after HSCT (13 to 319 days) [23]. HSCT-TMA is classified into four overlapping subtypes: multifactorial fulminant TMA, conditioning-associated HUS, cyclosporine A-associated nephrotoxicity with microangiopathic hemolytic anemia, and cyclosporine A-associated neurotoxicity with microangiopathic hemolytic anemia [24]. Multifactorial fulminant TMA and cyclosporine A-associated neurotoxicity with microangiopathic hemolytic anemia have poor prognoses, while the courses of condition-associated HUS and cyclosporine A-associated nephrotoxicity with microangiopathic hemolytic anemia are often milder.

Early identification of HSCT-TMA can be difficult. There is clinical overlap with calcineurin inhibitor toxicity, which can also cause red cell fragmentation, thrombocytopenia, renal dysfunction and neurological problems. Furthermore, many of the features of TMA may not be present initially or may be attributed to other causes. In particular, the platelet and red blood cell count may fall because engraftment may not have occurred. Similarly, minor red cell fragmentation is common after bone marrow transplantation, and a developing TMA may be overlooked. Finally, the early renal or neurological manifestations of HUS/TTP may be difficult to discern in ill patients on multiple medications. The incidence of HSCT-TMA may be no greater than in the general population [22], because of the frequent uncertainty of diagnosis, the variability of reported 
incidences, the potential for mimicry from other transplantation-related complications, and the absence of autopsy findings in most reports.

TMA has been reported after transplantation of all types of solid organs, although the majority of cases were after renal transplantation [25]. The United States Renal Data System has shown an incidence of $0.8 \%$ of de novo transplantation-associated TMA in renal transplantation [26], but single-center studies have reported incidences up to $14 \%[27,28]$. The risk of TMA is highest during the first 3 months after transplantation [26], and $96 \%$ of cases occur within 1 year [25]. TMA is usually associated with the use of calcineurin inhibitors [29], but sirolimus [30], vascular rejection [31], and multiple viral agents, including cytomegalovirus infection, have been implicated [32]. Of particular interest, acute vascular rejection can have clinical and histological features similar to those of TMA; therefore, accurate diagnosis is essential, as treatment varies considerably. While TMA is a result of primary, nonantibody mediated, injury to endothelial cells, the specific lesion for vascular rejection appears to be an antibodymediated endovasculitis. This acute humoral rejection results in the binding of antibodies to donor endothelium, which activate the classical complement pathway, causing deposition of $\mathrm{C} 4 \mathrm{~d}$ in the peritubular capillaries. $\mathrm{C} 4 \mathrm{~d}$ immunostaining of the renal biopsy tissue may be informative in cases where the diagnosis is unclear [33].

\section{Pathogenesis}

The risk factors for TMA after HSCT include allogenic transplantation, an unrelated stem-cell donor, acute graftversus-host disease, calcineurin inhibitors, rapamycin, hepatic veno-occlusive disease, cytomegalovirus, human herpes virus-6, parvovirus B19, and adenovirus [27, 34]. The pathogenesis may relate to underlying endothelial damage associated with radiotherapy, chemotherapy, calcineurin inhibitors, infection and, possibly, graft-versus-host disease. The pathophysiology of TMA after solid organ transplantation is believed to be secondary to an endothelial injury rather than an autoimmune process. ADAMTS13 levels are not markedly depressed in most cases of HSCTTMA [10, 35] or TMA associated with solid organ transplantation [29]. Regardless, the most important risk factors seem to be calcineurin inhibitors and anti-mTOR agents $[27,30]$, and the risk is increased when those agents are used together [27].

\section{Treatment}

There is no effective treatment for transplantation-associated TMA. The calcineurin inhibitor may be discontinued, but this may not reverse the TMA and may result in acute graft-versus-host disease [34]. Switching cyclosporine A to tacrolimus, or vice versa, occasionally results in recovery. Plasmapheresis and plasma exchange are currently not considered standards of care [21, 22]. Furthermore, the absence of severe ADAMTS13 deficiency provides no rationale for these potentially harmful interventions.

\section{Malignancy}

Clinical features and diagnosis

Malignancy associated TMA is mainly seen in adults and is associated with many different adenocarcinomas [34, 36]. Rarely, TMA may be associated with leukemia [37] or lymphoma [38]. Malignancy associated TMA may be manifested at any stage of the disease, from early in the course to widely disseminated cancer. When TMA is the first manifestation of an occult malignancy, patients present with abrupt onset of hemolytic anemia and thrombocytopenia; renal dysfunction is less common than in other forms of HUS/TTP [34].

\section{Pathogenesis}

The pathogenesis of malignancy associated TMA is multifactorial. ADAMTS13 levels in malignancy range from undetectable to normal $[10,36]$. Microvascular tumor emboli, tumor procoagulants, monocyte procoagulants, and impaired fibrinolysis may also be implicated [34].

Malignancy associated TMA may be triggered by chemotherapeutic agents (mitomycin $\mathrm{C}$ and gemcitabine). However, the occurrence of HUS/TTP in the absence of these agents suggests that some cases result from a paraneoplastic phenomenon [37-39]. Radiation exposure and opportunistic infections such as cytomegalovirus infection [40] contribute to the difficulty of assigning a cause. Furthermore, in disseminating malignancies, a syndrome resembling HUS/TTP can be mimicked by DIC.

Treatment

Treatment of the underlying cancer is the mainstay of therapy. When a chemotherapeutic agent is a suspected cause, attempts to decrease or discontinue the drug are considered. There is no role for plasmapheresis.

\section{Medications}

Many commonly prescribed medications, vaccines, illicit drugs, and exogenous substances are reported to be associated with TMA [41]. Most of the case reports are 
difficult to evaluate because of the possibility of a chance association, concomitant disease states, and exposure to multiple medications [41, 42]. The five most commonly reported TMA-associated agents are cyclosporine A, tacrolimus, mitomycin $\mathrm{C}$, quinine, and ticlopidine.

The calcineurin inhibitors are associated with TMA after solid organ or hematopoietic stem-cell transplantation. They also cause TMA in Behçet disease [43] and systemic sclerosis [44]. Healthy rhesus monkeys exposed to tacrolimus developed anemia with schistocytes, thrombocytopenia, and renal microangiopathy [45].

The incidence of transplant associated-TMA ascribed to cyclosporine $\mathrm{A}$ is $13 \%$ [28], and to tacrolimus it is $1 \%$ to $4.7 \%$ [46]. The onset of TMA may be associated with supra-therapeutic or therapeutic levels of cyclosporine A [41]. Cyclosporine A-associated TMA is often confined to the kidney but may be associated with hematological derangements. Endothelial toxicity induced directly by calcineurin inhibitors is mediated by thromboxane-induced vasoconstriction, alterations in prostacyclin synthesis, increased renin activity, increased endothelin secretion, and the reduced formation of activated protein $C[42,47]$ but not ADAMTS13 deficiency [48]. Treatment is withdrawal of the offending agent, although not all patients respond.

Many antineoplastic agents (bleomycin, cisplatin, gemcitabine) are associated with TMA, with mitomycin $\mathrm{C}$ most frequently reported $[41,42]$. It is likely that mitomycin $\mathrm{C}$ causes direct endothelial damage [49]. Treatment with plasma exchange is not effective, and overall prognosis is extremely poor [42].

Quinine, as a medication or food additive, is associated with TMA. In one series, $57 \%$ of cases of drug-associated HUS/TTP were ascribed to quinine. Patients exposed to quinine may develop autoantibodies against platelets, granulocytes, lymphocytes, and endothelial cells [42] but not against ADAMTS13 [35]. Quinine-associated TMA is not dose related, and re-exposure to one dose after many years can result in recurrence [42]. Treatment is withdrawal of the quinine. Use of plasmapheresis is based on uncontrolled trials.

The incidence of ticlopidine (an anti-platelet agent) associated TMA is $0.02-0.06 \%[50,51]$. In one series most patients had depressed ADAMTS13 activity and vWF-cleaving protease inhibitors [52]. Furthermore, all the patients completely recovered after discontinuation of ticlopidine and treatment with plasmapheresis. In contrast, a separate series of patients with ticlopidine-associated HUS/ TTP had normal to near normal ADAMTS13 levels [53]. In addition, ticlopidine was shown to induce apoptosis directly in cultured human microvascular endothelial cells by disrupting the normal endothelial cell-extracellular matrix interactions. These observations suggest that there are several causal pathways in ticlopidine-associated TMA.
Clopidogrel, a related compound, has replaced ticlopidine because of fewer side-effects. Clopidogrel less commonly causes HUS/TTP [42]. Treatment of ticlopidine-associated HUS/TTP involves cessation of the medication, and plasma exchange [42, 51].

\section{Unclassified}

Many conditions are listed as possible causes of HUS: infectious mononucleosis, Coxiella burnetii, group A beta hemolytic streptococcus, Salmonella typhi, hepatitis A, Kawasaki disease, and many others. Pregnancy has also been proposed as a risk factor, but this is complicated by pre-eclampsia, hemolytic anemia, elevated liver enzymes and low platelets (HELLP) syndrome, idiopathic TTP, factor $\mathrm{H}$ deficiency, and E. coli 0157:H7 infection during or after pregnancy.

\section{Conclusion}

Considerable progress has been made in the understanding of HUS, TTP, and TMA. The recognition of the importance of the Shiga toxins, neuraminidase activity, abnormalities in the vWF-cleaving protease, and regulatory elements of the complement cascade, has elevated some of these conditions from syndrome to the status of clinico-pathological diseases. The pathophysiology of many of the secondary causes of TMA remains unknown. Whether the ADAMTS13 activity will truly distinguish HUS from TTP in many problematic cases remains to be seen.

Acknowledgment Dr. L. Copelovitch is the 2004 Carol Lewis Pediatric Nephrology Fellow in The Division of Nephrology, The Children's Hospital of Philadelphia, USA.

Questions: (Answers appear after the reference list)

1. Which of the following should not be routinely treated by plasma exchange or infusion?
a. TTP
b. Factor $\mathrm{H}$ deficiency-associated HUS
c. Ticlopidine-associated HUS
d. TMA after hematopoietic stem cell transplantation
e. Congenital TTP (Upshaw-Schulman syndrome)

2. Which of the following contributes to the difficulty in establishing the diagnosis of TMA after hematopoietic stem cell transplant?

a. Clinical overlap with calcineurin toxicity

b. Delayed bone marrow engraftment 
c. The frequency of minor red cell fragmentation

d. Neurological and renal dysfunction can occur for many other reasons

e. All of the above

3. Which of the following is true regarding malignancy associated TMA.

a. Is a leading cause of HUS in children

b. Usually associated with lymphoma or leukemia

c. Can always be attributed to a chemotherapeutic agent

d. Renal dysfunction is less common than in other forms of secondary HUS/TTP

e. TMA never precedes the diagnosis of malignancy

4. Which of the following is true regarding SLE-associated HUS/TTP?

a. The onset of SLE usually precede HUS/TTP

b. Is always associated with APLS

c. A positive finding in a Coombs' test excludes the diagnosis of HUS/TTP

d. Has a mortality rate of $<10 \%$ when treated with plasmapheresis

e. Is always associated with a severe deficiency of ADAMTS13

5. Which of the following is not true regarding TMA after solid-organ transplantation?

a. Is most frequently associated with renal transplantation

b. Is usually diagnosed more than 12 months after transplantation

c. Is often confused with vascular rejection

d. Is usually associated with calcineurin inhibitors

e. ADAMTS13 levels are frequently normal

\section{References}

1. Besbas N, Karpman D, Landau D, Loirat C, Proesmans W, Remuzzi G, Rizzoni G, Taylor CM, Van de Kar N, Zimmerhackl LB; European Paediatric Research Group for HUS (2006) A classification of hemolytic uremic syndrome and thrombotic thrombocytopenic purpura and related disorders. Kidney Int 70:423-431

2. Symmers W (1952) Thrombotic microangiopathic haemolytic anaemia (thrombotic microangiopathy). BMJ ii:897-903

3. George JN, Selby GB (2004) Thrombotic microangiopathy after allogenic bone marrow transplantation: a pathologic abnormality associated with diverse clinical syndromes. Bone Marrow Transplant 33:1073-1074

4. Tsai HM (2004) Molecular mechanisms in thrombotic thrombocytopenic purpura. Semin Thromb Hemost 30:549-557

5. McLeod BC (2002) Thrombotic microangiopathies in bone marrow and organ transplant patients. J Clin Apheresis 17:118-123

6. Hamasaki K, Mimura T, Kanda H, Kubo K, Setoguchi K, Satoh T, Misaki Y, Yamamoto K (2003) Systemic lupus erythematosus and thrombotic thrombocytopenic purpura: a case report and literature review. Clin Rheumatol 22:355-358

7. Starck M, Abedinpour F, Dendorfer U, Wagner-Czekalla J, Pachmann M, Mann JF, Nerl C (2005) Acquired thrombotic thrombocytopenic purpura as the presenting symptom of systemic lupus erythematosus. Successful treatment with plasma exchange and immunosuppression - report of two cases. Eur J Haematol $75: 436-440$

8. Kapoulas S, Liakos S, Karkavelas G, Ageloudi M, Grekas D, Giannoulis E (2004) Thrombotic thrombocytopenic purpura associated with rapidly progressive lupus nephritis: report of two cases. Clin Nephrol 63:297-301

9. Amoura Z, Costedoat-Chalumeau N, Veyradier A, Wolf M, GhillaniDalbin P, Cacoub P, Meyer D, Piette JC (2004) Thrombotic thrombocytopenic purpura with severe ADAMTS-13 deficiency in two patients with primary antiphospholipid syndrome. Arthritis Rheum 50:3260-3264

10. Zheng XL, Kaufman RM, Goodnough LT, Sadler JE (2004) Effect of plasma exchange on plasma ADAMTS13 metalloprotease activity, inhibitor level, and clinical outcome in patients with idiopathic and nonidiopathic thrombotic thrombocytopenic purpura. Blood 103:4043-4049

11. Devinsky O, Petito CK, Alonso DR (1988) Clinical and neuropathological findings in systemic lupus erythematosus: the role of vasculitis, heart emboli, and thrombotic thrombocytopenic purpura. Ann Neurol 23:380-384

12. Veyradier A, Obert B, Houllier A, Meyer d, Girma JP (2001) Specific von Willebrand factor-cleaving protease in thrombotic microangiopathies: a study of 111 cases. Blood 98:1765-1772

13. Porta C, Caporali R, Montecucco C (1999) Thrombotic thrombocytopenic purpura and autoimmunity: a tale of shadows and suspects. Haematologica 84:260-269

14. Espinoza G, Bucciarelli S, Ervera R, Lozano M, Reverter JC, de la Red G, Gil V, Ingelmo M, Font J, Asherson RA (2004) Thrombotic microangiopathic hemolytic anaemia and antiphospholipid antibodies. Ann Rheum Dis 63:730-736

15. Alpers CE (2003) Light at the end of the TUNEL: HIV-associated thrombotic microangiopathy. Kidney Int 63:385-396

16. Sahud MA, Claster S, Liu L, Ero M, Harris E, Furlan M (2001) von Willebrand factor-cleaving protease inhibitor in a patient with human immunodeficiency syndrome-associated thrombotic thrombocytopenic purpura. Br J Haematol 116:909-911

17. Gadallah MF, el-Shahway MA, Campese VM, Todd JR, King JW (1996) Disparate prognosis of thrombotic microangiopathy in HIV-infected patients with and without AIDS. Am J Nephrol $16: 446-450$

18. Peraldi MN, Maslo C, Akposso K, Mougenot B, Rondeau E, Sraer JD (1999) Acute renal failure in the course of HIV infection: a single institution retrospective study of ninety two patients and sixty renal biopsies. Nephrol Dial Transplant 14:1578-1585

19. Pardo V, Zilleruelo G, Abitol C, Rojas-Rodrigues E, Straus J (1994) HIV associated nephropathy (HIVAN) in children: clinicopathologic manifestations (abstract). J Am Soc Nephrol 5:357

20. Novitzky N, Thomson J, Abrahams L, du Toit C, McDonald A (2005) Thrombotic thrombocytopenic purpura in patients with retroviral infection is highly responsive to plasma infusion therapy. Br J Haematol 128:373-379

21. Ho VT, Cutler C, Carter S, Martin P, Adams R, Horowitz M, Ferrara J, Soiffer R, Giralt S (2005) Blood and marrow transplant clinical trials network toxicity committee consensus summary: thrombotic microangiopathy after hematopoietic stem cell transplantation. Biol Blood Marrow Transplant 11:571-575

22. George JN, Li X, McMinn JR, Terrell DR, Vesley SK, Selby GB (2004) Thrombotic thrombocytopenic purpura-hemolytic uremic syndrome following allogenic HPC transplantation: a diagnostic dilemma. Transfusion 44:294-304 
23. Ruutu T, Hermans J, Niederwieser D, Gratwohl A, Kiehl M, Volin L, Bertz H, Ljungman P, Spence D, Verdonck LF, Prentice HG, Bosi A, Du Toit CE, Brinch L, Apperley JF; EBMT Chronic Leukaemia Working Party (2002) Thrombotic thrombocytopenic purpura after allogeneic stem cell transplantation: a survey of the European Group for Blood and Marrow Transplantation (EBMT). Br J Haematol 118:1112-1119

24. Pettitt AR, Clark RE (1994) Thrombotic microangiopathy following bone marrow transplantation. Bone Marrow Transplant 14:495-504

25. Singh N, Gayowski T, Marino IR (1996) Hemolytic uremic syndrome in solid-organ transplants. Transpl Int 9:68-75

26. Reynolds JC, Agodoa LY, Yuan CM, Abbott KC (2003) Thrombotic microangiopathy after renal transplantation in the United States. Am J Kidney Dis 42:1058-1068

27. Ponticelli C, Banfi G (2006) Thrombotic microangiopathy after kidney transplantation. Transpl Int 19:789-794

28. Zarifian A, Meleg-Smith S, O'Donovan R, Tesi RJ, Batuman V (1999) Cyclosporine-associated thrombotic microangiopathy in renal allografts. Kidney Int 55:2457-2466

29. Mal H, Veyradier A, Brugiere O, Da Silva D, Colombat M, Azoulay E, Benayoun L, Rondeau E, Dauriat G, Taille C, Leseche G, Castier Y, Fournier M (2006) Thrombotic microangiopathy with acquired deficiency in ADAMTS 13 activity in lung transplant recipients. Transplantation 81:1628-1632

30. Fortin MC, Raymond MA, Madore F, Fugere JA, Paquet M, St-Louis G, Hebert MJ (2004) Increased risk of thrombotic microangiopathy in patients receiving a cyclosporin-sirolimus combination. Am J Transplant 4:946-952

31. Mor E, Lustig S, Tovar A, Bar-Nathan N, Shharabani E, Shapira Z, Yusim A (2000) Thrombotic microangiopathy early after kidney transplantation: hemolytic uremic syndrome or vascular rejection? Transplant Proc 32:686-687

32. Ramasubbu K, Mullick T, Koo A, Hussein M, Henderson JM, Mullen KD, Avery RK (2003) Thrombotic microangiopathy and cytomegalovirus in liver transplant recipients: a case-based review. Transpl Infect Dis 5:98-103

33. Chan GSW, Tse KC, Lam MF, Chan KW (2006) Thrombotic microangiopathy in an allograft kidney: a diagnostic challenge. Histopathology 48:775-776

34. Qu L, Kiss JE (2005) Thrombotic microangiopathy in transplantation and malignancy. Semin Thromb Hemost 31:691-699

35. Vesley SK, George JN, Lammle B, Studt JD, Alberio L, ElHarake MA, Raskob GE (2003) ADAMTS 13 activity in thrombotic thrombocytopenic purpura-hemolytic uremic syndrome: relation to presenting features and clinical outcomes in a prospective cohort of 142 patients. Blood 102:60-68

36. Fontana S, Gerritsen HE, Kremer Hovinga J, Furlan M, Lammle B (2001) Microangiopathic haemolytic anemia in metastasizing malignant tumors is not associated with a severe deficiency of the von Willebrand factor-cleaving protease. Br J Haematol 113:100-102

37. Hahn H, Ha IS, Choi HS, Shin HY, Cheong HI, Ahn HS, Choi Y (2003) Acute leukemia: an association with atypical hemolytic uremic syndrome. Pediatr Nephrol 18:703-705

38. Still H, Hofler G, Kaufmann P, Horina J, Spuller E, Kleinert R, Beham-Scmid C (1995) Angiotropic large cell lymphoma presenting as thrombotic microangiopathy (thrombotic thrombocytopenic purpura). Cancer 75:1167-1170

39. Wolff D, Brinkmann B, Emmrich J, Steiner M (2003) Metastatic pancreatic carcinoma presenting as thrombotic thrombocytopenic purpura. Pancreas 26:314
40. Cavagnaro F, Barriga F (2000) Hemolytic uremic syndrome in a child with leukemia and cytomegalovirus infection. Pediatr Nephrol 14:1118-1120

41. Medina PJ, Sipols J, George JN (2001) Drug-associated thrombotic thrombocytopenic purpura-hemolytic uremic syndrome. Curr Opin Hematol 8:286-293

42. Zakarija A, Bennett C (2005) Drug-induced thrombotic microangiopathy. Semin Thromb Hemost 31:681-690

43. Chatterjee A, D'Souza RJ (1997) Haemolytic uraemic syndrome during cyclosporin therapy for Behcet's disease. Nephrol Dial Transplant 12:2799-2800

44. Zachariae H, Hansen HE, Olsen TS (1992) Hemolytic uremic syndrome in a patient with systemic sclerosis treated with cyclosporin A. Acta Derm Venereol 72:307-309

45. Kindt MV, Kemp R, Allen HL, Jensen RD, Patrick DH (1999) Tacrolimus toxicity in rhesus monkey: model for clinical side effects. Transplant Proc 31:3393-3396

46. Trimarchi HM, Truong LD, Brennan S, Gonzalez JM, Suki WN (1999) FK506-associated thrombotic microangiopathy: report of two cases and review of the literature. Transplantation 67:539-544

47. Perico N, Zoja C, Benigni A, Ghilardi F, Gualandris L, Remuzzi G (1986) Effect of short-term cyclosporine administration in rats on renin-angiotensin and thromboxane A2: possible relevance to the reduction in glomerular filtration rate. J Pharmacol Exp Ther 239:229-235

48. Elliott MA, Nichols WL Jr, Plumhoff EA, Ansell SM, Dispenzieri A, Gastineau DA, Gertz MA, Inwards DJ, Lacy MQ, Micallef IN, Tefferi A, Litzow M (2003) Posttransplantation thrombotic thrombocytopenic purpura: a single-center experience and a contemporary review. Mayo Clin Proc 78:421-430

49. Cattell V (1985) Mitomycin-induced hemolytic uremic kidney. An experimental model in the rat. Am J Pathol 121:88-95

50. Steinhubl SR, Tan WA, Foody JM, Topol EJ (1999) Incidence and clinical course of thrombotic thrombocytopenic purpura due to ticlopidine following coronary stenting. EPISTENT Investigators. Evaluation of platelet IIb/IIIa inhibitor for stenting. JAMA 281:806-810

51. Bennett CL, Kiss JE, Weinberg PD, Pinevich AJ, Green D, Kwaan HC, Feldman MD (1998) Thrombotic thrombocytopenic purpura after stenting and ticlopidine. Lancet 352:1036-1037

52. Tsai HM, Rice L, Sarode R, Chow TW, Moake JL (2000) Antibody inhibitors to von Willebrand factor metalloproteinase and increased binding of von Willebrand factor to platelets in ticlopidine-associated thrombotic thrombocytopenic purpura. Ann Intern Med 132:794-799

53. Mauro M, Zlatoposkiy A, Raife TJ, Laurence J (2004) Thienopyridine-linked thrombotic microangiopathy: association with endothelial cell apoptosis and activation of MAP kinase signaling cascades. Br J Haematol 124:200-202

\section{Answers:}

1. d

2. e

3. d

4. a

5. b 